"Clearly it is only temporarily recessive." [Precisely.]

" 3 . How is the recessive element expressed in $F_{1}$ ? It has not disappeared, as it reappears in $F_{2}$ unaltered. It is not expressed in the 'soma' of the plant: Where is it?" [Answer: In its germ cells.]

Dr. Hart's amended Mendelian scheme on p. 43 may be all right, but we cannot understand it, and we know of no experimental evidence for the assertion that there are three kinds of zygotes in $F_{1}$, a talltall, $\left\{\begin{array}{c}\text { tall } \\ \text { dwarf }\end{array}\right\}$ tall, and a dwarf-tall. The reader must examine Dr. Hart's argument for himself.

The account of biometry is not very illuminating. "Galton," we are told, "formulated certain laws, which are important-that of filial regression, for instance; but the most widely known one, Galton's law, setting forth the supposed fractions making up the full heredity in the individual, is of great importance, and has been specially fought over since Mendelism began to exert its sway over Evolution. . . . We may therefore, using Mendel's term of unitcharacter, say that, according to Galton, offspring inherit one-half of their unit-characters from their parents, and the most of the other half from the grandparents and great-grandparents."

And, again :-

"The amount of hard work by biometricians in accumulating measurement-facts and noting minute variations is enormous. We get a good illustration of that in some of the late Francis Welldon's [sic] work. This eminent biologist was a most eminent follower [!] of biometric work, and ... we see how Welldon spent himself, sometimes successfully and sometimes unfortunately, it must be said unsuccessfully, in arduous observations, unremunerative as yet in scientific deduction."

We cannot agree with this definition of biometrv in the glossary at the end of the book, "Biometry is concerned with accurate measurements of 'organs,' their relations, and the laws governing their occurrence." It grieves us not to be inclined to praise this book, for the author is so manifestly earnest. But earnestness is not a sufficient qualification for authorship, and we cannot persuade ourselves that the book meets a long-felt want.

\section{PHANTASMS OF THE LIVING.}

Théorie Physico-chimique de la Vie et Générations Spontanées. By Prof. Stéphane Leduc. Pp. 202. (Paris: A. Poinat, 1910.) Price 5 francs.

PROF. LEDUC is not one of those who exaggerates the apartness of life. $\mathrm{He}$ thinks that the differences between an animate and an inanimate system are differences of degree, not of kind. It is in vain, he says, that one seeks for any exclusive characteristic of living things; it cannot be found in development, or nutrition, or irritability, or growth, or organisation, or reproduction. One discovers in living creatures only those physical forces which operate in the not-living world; biology, indeed, is part of the physica-chemistry of fluids. These conclusions are based partly on general reasoning, which appears to us fallacious, and partly on an interesting series of experiments, of which some illusNo. 2 I6g, VOL. 86] trations may be given. A solution of 5 to 6 per cent. pure gelatine is spread on a slide; on this at regular intervals of 5 to $6 \mathrm{~mm}$. one places by means of a pipette drops of ferrocyanide of potassium; these diffuse and meet and dry, giving a result like a tissue. The "artificial cells" pass through three stages of organisation, equilibration, and decline-ending, of course, in "death."

With a little ink and water one can conjure up all sorts of phantasms, some of them yielding very striking suggestions of karyokinesis. Periodic precipitations due to waves of diffusion may result in the artificial production of mother-of-pearl, which we can well believe, but we are not impressed by the "curious analogy" between some of the forms and "articulate animals." One of the figures is a little like a squashed scorpion, but is this sort of thing useful?

Prof. Leduc contributes an interesting short history of the biological study of osmotic phenomena, referring to Nollet, Rose, Traube, Harting, Quincke, and many others, and he gives a number of remarkable figures - the precise nature of which is in most cases left unstated-showing his own osmotic creations, produced by placing a fragment of calcium chloride in a saturated solution of carbonate of potash or tribasic phosphate of potash, or in similar ways. A fruitful solution to work with consists of $60 \mathrm{gr}$. of silicate of potash at $33^{\circ}, 60 \mathrm{gr}$. of saturated solution of carbonate of soda, $30 \mathrm{gr}$. of saturated solution of di-basic phosphate of soda, and distilled water to make up a litre. Into this are placed fragments of chloride of calcium, and remarkable osmotic growths result. Some of the pictures of these and similar growths are mushroom-like, others worm-like, others coral-like, others shell-like, others mould-like, others leaf-like, and when a number are grouped together on a plate the effect is very quaint.

There can be little doubt that a study of these growths may in the course of time throw some light on the role of osmosis in organic growth. We think, however, that the author is going far beyond 'his results when he says that these osmotic growths exhibit "nutrition, assimilation, elimination, and irritability." The need of proof-reading is so conspicuous in this volume that we must direct attention to it. We read of Ernest Hcekel, Ulenhuth, Buttler Burke de Crambridge, Bütsehli, and so on; there are three or four errors in the title of a book by Rhumbler; and we see a German word with an accent. These are minute details, but they are congruent with the impetuous superficiality of the main thesis of the book.

\section{IRRIGATION WORKS.}

Notes on Irrigation Works. A Course of Lectures delivered at Oxford under the auspices of the Common University Fund. By N. F. Mackenzie. Pp. ix + III. (London: Constable and Co., Ltd., I910.) Price $7 s .6 d$. net.

THESE lectures in book form have as their author 1 an engineer whose competency to deal with his subject is sufficiently established by the fact that he was selected to be Under Secretary 